- Embora os empregados de conselhos de fiscalização de profissões regulamentadas sejam regidos pela legislação trabalhista, tal condição não os exime da sujeição ao concurso público.

\title{
TRIBUNAL DE CONTAS DA UNIÃO
}

Proc. TC 400.088/97

GRUPO I - CLASSE II - 2a Câmara TC-400.088/97-5

Natureza: Prestação de Contas, exercício de 1996.

Entidade: Conselho Regional de Contabilidade de Mato Grosso do Sul - CRC/MS.
Responsáveis: Dorgival Benjoino da Silva, Presidente, e outros.

EMENTA: Prestação de Contas. Contratação de pessoal sem concurso público. Diligências. Entendimento da Corte, nos casos como o da espécie, no sentido da regularidade 
com ressalva das contas e determinação às entidades para que se abstenham de admitir pessoal sem a realização de prévio concurso público, ante o disposto no art. 37 , II, da Constituição Federal, e na Súmula n. 231 da Jurisprudência deste Tribunal. Contas regulares com ressalva. Quitação aos responsáveis. Determinação.

\section{RELATÓRIO}

Trata o presente processo da Prestação de Contas de Conselho Regional de Contabilidade de Mato Grosso do Sul - CRC/MS, relativa ao exercício de 1996.

2. A Secretaria de Controle Interno do Ministério do Trabalho - CISET/MTb emitiu Certificado de regularidade com ressalva das presentes contas (fls. 127/128), tendo a autoridade ministerial declarado ter tomado conhecimento (fls. 131).

3. A SECEX/MS, ao instruir o feito às fls. $139 / 140$, considerando que as contas evidenciam impropriedades de natureza formal, já devidamente saneadas, propôs fossem julgadas regulares com ressalva, dando-se quitação aos responsáveis.

4. No entanto, o douto Ministério Público, por meio do Parecer da lavra da Exma. Sra. Procuradora Maria Alzira Ferreira - por verificar que consta “do Relatório de Gestão (fls. 17) que, no exercício de 1996, foram contratados, pelo regime da Consolidação das leis do Trabalho - CLT, três funcionários para suprir o setor de fiscalização, não havendo informação acerca da realização de concurso público para sua efetivação, consoante disposição contida no art. 37, II, da Constituição Federal" - opinou pela realização de diligência, a fim de que fosse esclarecida essa questāo.

5. Em nova manifestação nos autos, a supramencionada Procuradora assim se pronuncia, no essencial (fls. 171/176):

“3. Em resposta à diligência, o Presidente do CRC/MS encaminhou o Of. $\mathrm{n}^{\mathrm{e}}$ 302/97PRES., de 30.10 .97 (f. 145/146), manifestando-se, preliminarmente, pelo arquivamento do processo, com base no art. $58, \S \S 1^{2}$ e $4^{\circ}$ da Medida provisória n 1.549-35, de 09.10.97.

4. Em seguida, escreve:

'Assim, a partir de 10/10/97, o Conselho Regional de Contabilidade do Mato Grosso do Sul não tem qualquer vínculo com entidade fora do Sistema CFC/CRC, inclusive com o Tribunal de Contas da União.

O Conselho Regional de Contabilidade do Mato Grosso do Sul não é, nem nunca foi autarquia. Nāo integra, nem nunca integrou o campo da Administração Pública.

$O$ art. $8^{2}$ do Decreto-Lei $n^{2} 1.040 / 69$, declara que aos empregados dos Conselhos de Contabilidade se aplica o regime da Consolidação das Leis do Trabalho.

Seus empregados são optantes pelo FGTS. $\mathrm{O}$ art. 37, da Constituição reporta-se à Administração Pública. $O$ Conselho não a integra.

Os empregados do Conselho não desempenham cargo público. Este só estabelecido em lei.

O Conselho não recebe qualquer tipo de renda oriunda dos cofres públicos.

Aos empregados se aplica a CLT, nos termos da Medida Provisória $n^{2} 1.549$, e o citado Decreto-Lei n 1.040/69.

Os cargos e contrataçōes são disciplinados por atos normativos do Conselho.

O procedimento de contratação de empregados é o mesmo adotado desde a criação do Conselho, o qual é seguido por todos os demais Conselhos Regionais de Contabilidade do país.' (Grifamos)

5. Ao analisar a resposta do Presidente do CRC/MS, a SECEX/MS, considerando que as informaçōes prestadas não esclareceram a questão da realização, do concurso público para a contratação dos três servidores, opinou pela realização de nova diligência objetivando informaçōes sobre a forma adotada para a contratação. Solicitou, ainda, cópia dos atos normativos internos que regulam a matéria.

6. Atendendo à segunda diligência, o Presidente do $\mathrm{CRC} / \mathrm{MS}$ enviou o documento de folhas $155 / 156$, explicando o processo adotado pelo conselho para a contratação de pessoal, acompanhado do Regulamento de Pes- 
soal e Plano de Cargos e Salários do CRC/MS (f. 157/168).

7. Na última análise do processo, a Unidade Técnica, no quadro SINOPSE DAS FALHAS VERIFICADAS, registrou o seguinte:

'Contratação de três funcionários para atuar no setor de fiscalização sem concurso público, por processo seletivo próprio, conforme esclarece o Presidente do CRC às fls. 155/156. A presente questāo sobre o regime jurídico a que estāo subordinados os servidores dos Conselhos está sendo questionado pelo Conselho Federal de Odontologia por intermédio do Mandado de Segurança n 21.797/9 que se encontra pendente de apreciação definitiva pelo Supremo Tribunal Federal. Assim, propomos dar continuidade ao feito adotando-se decisāo similar àquelas contidas nos TCS ns $300.117 / 97-3,375.248 / 97-8$ e $550.160 / 97-3$ que julgaram as contas daqueles Conselhos regulares com ressalva, dando quitação aos responsáveis indicados, sem prejuizo de determinar aos referidos Conselhos para que observem os princípios constitucionais, aplicáveis à contratação de pessoal, em especial o disposto no art. 37, II.'

Na CONCLUSĀO da análise escreve:

'Diante do exposto, submetemos os autos à consideração superior, propondo que as contas sejam julgadas regulares com ressalva, dando-se quitação aos responsáveis, Srs. Dorgival Benjoino da Silva e outros, arrolados às fls. 02, nos termos do artigos $1^{2}$, inciso $I, 16$, inciso II, 18 e 23, inciso II, da Lei ne 8.443/92, considerando que as contas evidenciam impropriedades de natureza formal, relatadas nos subitem 4 desta instrução, que não resultaram dano ao Erário, sem prejuízo de se determinar ao mencionado Conselho que se abstenha de admitir pessoal sem a realização de concurso público, ante o tenha de admitir pessoal sem a realização de concurso público, ante o disposto no art. 37, II, da Constituição Federal, e na Súmula 231, da jurisprudência deste Tribunal'.

8. Por fim, em 23.07 .98 , foi protocolizado neste Tribunal o OFÍCIO CJU/CFC no 1.261/98, de 10.07.98, do Conselho Federal de Contabilidade (anexado à contracapa), assinado pelo seu procurador Pedro Miranda, mediante o qual manifesta seu inconformismo com o pedido de diligência quanto à contratação de pessoal, alegando que a Lei $n^{\underline{0}}$ $9.649 / 98$, no seu art. $58, \S 3^{2}$, declara que os empregados dos Conselhos de Fiscalização são regidos pela CLT e que fica vedada qualquer relação com a Administração.

Diz, ainda, que:

'Os Conselhos são dotados de personalidade jurídica de direito privado.

$\mathrm{Na}$ entidade de direito privado, inexistem servidores públicos.

A referida lei prescreve que o controle das atividades financeiras e administrativas dos Conselhos de Fiscalização de Profissões Regulamentadas será realizado pelos seus órgãos internos. Os Conselhos Regionais prestarão contas ao Conselho Federal e este àqueles.

A norma legal cortou toda e qualquer ligação dos Conselhos com o Eg. Tribunal de Contas da União.

Diante do exposto, requer o arquivamento do referido processo, eis que o $\mathrm{Eg}$. Tribunal de Contas da União não se reveste de autarquia Conselho de Contabilidade.'

\section{II}

9. Relativamente ao conteúdo do Of. $n^{\mathbf{2}}$ 302/97-PRES. (f. 145/146 e itens 3 e 4 deste parecer) cabe observar que:

12 - Embora o responsável não tenha consignado na transcrição do $\S 4^{\circ}$ do art. 58 da MP $n^{2}$ 1.544-35 que o controle das atividades financeiras e administrativas seria realizado exclusivamente pelos seus órgãos internos de controle, a $36^{a}$ edição da citada medida provisória, publicada no DOU de 06.11.97, excluiu o termo exclusivamente do parágrafo correspondente $(\$ 50)$.

$2^{2}$ - A 35a ediçāo da Medida Provisória nª 1.549 , de 09.10.97, citada pelo ilustre Presidente do CRC/MS, também dispunha que:

' $\$ 32$ Constituirāo receitas dos conselhos as contribuições anuais devidas por pessoas físicas ou jurídica, fixadas pela assembléia geral, bem como multas, taxas e emolumentos estabelecidos em lei.' (Grifamos).

3- A $36^{\mathrm{a}}$ edição da Medida Provisória nº 
1.549 , de 06.11 .97 , e seguintes, alteram a re-

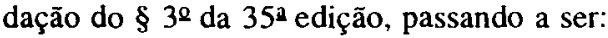

' $\$ 4^{2}$ Os conselhos de fiscalização de profissōes regulamentadas, existentes até 10 de outubro de 1997, ficam autorizados a cobrar e executar as contribuições anuais devidas por pessoas físicas ou jurídicas, bem como taxas e emolumentos instituídos em lei.' (Grifamos).

40- Por fim, com a edição da Lei n" 9.649, de 27.05.98, o art. 58 da Medida Provisória $\mathrm{n}^{2} 1.549$ passou a ter a seguinte redação:

'Art. 58. Os serviços de fiscalização de profissōes regulamentadas serão exercidos em caráter privado, por delegação do Poder Público, mediante autorização legislativa.

$\S 1^{2}$ A organização, a estrutura e o funcionamento dos conselhos de fiscalização de profissões regulamentadas serão disciplinados mediante decisão do plenário do conselho federal da respectiva profissão, garantindo-se que na composição deste estejam representados todos seus conselhos regionais.

$\S 2^{2}$ Os conselhos de fiscalização de profissões regulamentadas, dotados de personalidade jurídica de direito privado, nāo manterão com os órgãos da Administração Pública qualquer vínculo funcional ou hierárquico.

$\S 3^{\circ}$ Os empregados dos conselhos de fiscalização de profissōes regulamentadas sāo regidos pela legislaçāo trabalhista, sendo vedada qualquer forma de transposição, transferência ou deslocamento para o quadro da Administração Pública direta ou indireta.

$\S 4^{2}$ Os conselhos de fiscalização de profissões regulamentadas são autorizados a fixar, cobrar e executar as contribuições anuais devidas por pessoas físicas e jurídicas, bem como preços de serviços e multas, que constituirão receita próprias, considerando-se título executivo extrajudicial a certidão relativa aos créditos decorrentes.

$\S 5^{2} \mathrm{O}$ controle das atividades financeiras e administrativas dos conselhos de fiscalização de profissōes regulamentadas, será realizado pelos seus órgãos internos, devendo os conselhos regionais prestar contas, anualmente, ao conselho federal da respectiva profissão, e estes aos conselhos regionais.

$\S 6$ Os conselhos de fiscalização de profis- sões regulamentadas, por constituírem serviço público, gozam de imunidade tributária total em relação aos seus bens, rendas e serviços.

$\S 72$ Os conselhos de fiscalização de profissōes regulamentadas promoverão, até 30 de junho de 1998, a adaptação de seus estatutos e regimentos ao estabelecido neste artigo.

$\$ 8^{2}$ Compete à Justiça Federal a apreciação das controvérsias que envolvam os conselhos de fiscalização de profissões regulamentadas, quando no exercício dos serviços a eles delegados, conforme disposto no caput.

$\S 9^{\circ} \mathrm{O}$ disposto neste artigo não se aplica à entidade de que trata a Lei $n^{\ell} 8.906$, de 4 de julho de 1994.' (Grifamos).

Vê-se, portanto, que os elementos constantes do $\S 4^{\circ}$ do art. $5^{\varrho}$ da Lei $n^{2} 9.649 / 98$ são típicos da atividade da administraçāo pública, que os delega, aos serviços de fiscalização de profissōes regulamentadas.

Assim, como aceitar que um órgão que tenha entre suas atividades-fim a atribuição de fixar, cobrar e executar as contribuiçōes parafiscais, preços de serviços e multas, esteja excluído do Poder Público. Daí a razão de sua subordinação ao Tribunal de Contas da União.

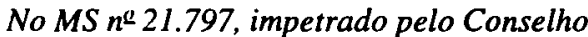
Federal de Odontologia contra o TCU, o Ministro-Relator, Carlos Mário Veloso, no seu voto expôs:

'Esclareça-se, ademais, que as contribuições cobradas pelos conselhos de fiscalização das profissões têm caráter tributário, porque são contribuições de interesse de categorias profissionais, assim contribuiçōes corporativas - C.F., art. 149. Reporto-me, no ponto, ao voto que proferi por ocasião do julgamento do RE 138.284-CE, em que analisei e discuti, amplamente, o tema das contribuiçōes parafiscal (RTJ 143/313)'. (Transcriçāo da p. 167 da Ata n 41/96-P-TCU).

$5^{2}$ - Relativamente à afirmação de que "o art. 37 da Constituição reporta-se à Administraçāo Pública. O conselho não a integra", cumpre lembrar que o $\S 6^{2}$ da Lei $n^{2} 9.649 / 98$ diz, expressamente, que os conselhos de fiscalização de profissōes regulamentadas se constituem em serviço público. 
'Serviço público é todo aquele prestado pela Administração ou por seus delegados, sob normas e controles estatais, para satisfazer necessidades essenciais ou secundárias da coletividade, ou simples conveniências do Estado." (Hely Lopes Meirelles, Direito Administrativo Brasileiro, $16^{a}$ ediçāo, Editora, Revista dos Tribunais, p. 290).

$6^{\circ}$ - Embora o $\S 30$ da Lei $n^{2}$ 9.649/98 estabeleça que os empregados dos conselhos de fiscalização de profissões regulamentadas são regidos pela legislação trabalhista, tal condiçāo não os exime da sujeição ao concurso público. No Mandado de Segurança n 21.322-DF impretado por Telma Leite Morais e outro contra o TCU, indeferido, por maioria, em Sessão Plenária do STF, de 03-12-92, o eminente Ministro Néri da Silveira, ao acompanhar o ilustre Ministro-Relator, conhecendo do mandado de segurança e o indeferindo, assim redigiu o seu voto:

'O Sr. Ministro Néri da Silveira: Sr. Presidente. A regra do art. 37, II, da Constituição, é abrangente de investidura em cargo ou emprego público, ao estipular que, em qualquer das hipóteses, há dependência de aprovação prévia em competitório de provas e títulos ressalvadas as nomeaçōes para cargo em comissão, declarado em lei de livre nomeação e exoneração.

Pouco importa se a investidura há de se fazer segundo vínculo funcional estatutário, ou conforme o regimento da CLT. Dessa maneira, não há conflito entre o que se estabelece no art. 37 , II, e o que está no art. 173 da Constituição, de maneira a entender-se que a última regra é excludente da incidência do art. 37, II, da Lei Maior, quando se trata de investidura e emprego em empresas que realizem exploração direta de atividade econômica pelo Estado.'

$7^{2}$ - Não obstante as novas disposiçōes relativas aos conselhos de fiscalização de profissōes regulamentadas (art. 58 da Lei $\mathrm{n}^{2}$ 9.649/98), o colendo Supremo Tribunal federal vem, reiteradamente, afirmando que tais conselhos são autarquias. (MS 21.466-DF, MS 22.643-SC).

$8^{\circ}$ - Sendo os serviços de fiscalização de profissões regulamentadas autarquias, perten- centes, portanto, à administração indireta (Decreto-lei $n^{2} 200 / 67$, art. 4, II, a), devem sujeitar-se às disposições dos arts. 37 e 39 da $\mathrm{CF} / 88$.

10. Quanto aos documentos de folhas 155/168 (resposta à segunda diligência) entendemos que:

$1^{2}$ - O procedimento adotado pelo CRC/MS para recrutamento e seleção do seu pessoal não caracteriza o concurso público exigido pela $\mathrm{CF} / 88$, para a investidura em cargo ou emprego público.

$2^{2}$ - $O$ fato de ser este o procedimento adotado desde a instalaçāo daquele Conselho Regional não justifica a sua continuidade.

11. Com relação ao ofício anexado à contracapa, considerando serem os argumentos ali expostos os mesmos de Of. $n^{\circ}$ 302/97PRES., de 30.10 .97 (f. 145/436), já comentados no item 9 deste parecer, deixaremos de tecer outras consideraçōes. Apenas, esclareceríamos, que "a autoridade de ordem legal, para proceder julgamento de processo envolvendo Conselho de Contabilidade", com a qual se reveste o Eg. Tribunal de Contas da Uniāo, está insculpida na nossa Lei Maior (art. 71, inciso II).

\section{III}

12. Em conclusão, considerando que a aprovação em concurso público de provas ou de provas e títulos é pressuposto jurídico exigido pela Constituiçāo Federal/88 (art. 37, II, primeira parte), para a investidura em cargo ou emprego público, na administração direta, indireta ou fundacional de qualquer dos Poderes da Uniāo, dos Estados, do Distrito Federal e dos Municípios, bem como princípios constitucional explícito, opinamos pela ilegalidade das admissões.

13. Manifestamo-nos, ainda, pela regularidade das presentes contas, com ressalva."

6. É o relatório.

\section{VOTO}

Importa destacar que a edição da Medida 
Provisória n. 1.549-35, de 09.10.97, ensejou determinação do Presidente desta Corte no sentido de que fossem realizados estudos acerca da orientação a ser adotada no exame dos processos relativos aos Conselhos de Fiscalização de Profissões Liberais (Comunicação da Presidência, 15.10.97).

2. Os mencionados estudos, objeto do TC$001.288 / 98-9$, foram submetidos a este Tribunal na Sessāo reservada de 07.10.98, oportunidade na qual o Plenário firmou o entendimento de que os referidos Conselhos estão obrigados a prestar contas a este Tribunal, em face do disposto nos arts. $5^{\circ}, 6^{\circ}, 7^{2}$ e $8^{\circ}$ da Lei n. 8.443/92 (Decisão n. 701/98 - in Ata n. 41/98).

3. Ressalte-se, ainda, que foram propostas perante o Supremo Tribunal Federal as Ações Diretas de inconstitucionalidade de ns. 1.717-6 e 1.847-7, questionando o art. $48 \mathrm{e}$ seus parágrafos da MP 1.549-36, de 06/1 1/97, e da Lei n. 9.649/98, tendo sido a primeira delas interposta por partidos políticos com representação no Congresso Nacional, invocando, entre outros dispositivos constitucionais, os arts. 70 e 71 , inciso II.

4. Seja qual for o entendimento que venha a prevalecer no tocante à personalidade jurídica de tais entidades, releva considerar que este Tribunal vem decidindo determinar aos mencionados Conselhos que se abstenham "de admitir pessoal sem a realização de prévio concurso público, ante o disposto no art. 37, II, da Constituiçāo Federal, e na Súmula 231 da Jurisprudência deste Tribunal" (v.g., Acórdão n. 209/98 - TCU/2a Câmara - in Ata n. 18/98; Acórdão n. 212/98 - TCU/2a Câmara - In Ata n. 19/98: Acórdão n. 213/98 - TCU/2a Câmara — in Ata n. 19/98; Acórdão n. 248/98 - TCU/2a Câmara - in Ata n. 24/98; Acórdão n. 313/98 - TCU/2a Câmara - in Ata n. 30/98; Acórdão n. $329 / 98$ — TCU/2a Câmara - in Ata n. 31/98; Acórdão n. 390/98 - TCU/2a Câmara - in Ata n. 35/98):

Ante o exposto, acolho, in totum, o parecer da Unidade Técnica e voto por que seja adotada a decisāo, sob a forma de acórdão, que ora submeto à apreciação desta Câmara.

Sala das Sessōes, em 26 de outubro de 1998
JOSÉ ANTONIO B. DE MACEDO, Relator

\section{ACÓRDĀO № 424/98 - TCU - 2a Câmara}

1. Processo TC n. 400.088/97-5.

2. Classe de Assunto: II - Prestação de Contas, exercício de 1996.

3. Entidade: Conselho Regional de Contabilidade de Mato Grosso do Sul - CRC/MS.

4. Responsáveis: Dorgival Benjoino da Silva, Denizard da Silveira Campos Filho, José Odair Gasparini, Rosângela Pereira de Souza, Osmar Figueiredo Bernardo.

5. Relator: Ministro José Antonio Barreto de Macedo.

6. Representante do Ministério Público: Dra. Maria Alzira Ferreira.

7. Unidade Técnica: SECEX/MS.

8. Acórdāo:

VISTOS, relatados e discutidos estes autos de Prestação de Contas de Conselho Regional de Contabilidade de Mato Grosso do Sul CRC/MS - relativa ao exercício de 1996.

Considerando que a CISET/MTb certificou a regularidade das contas com ressalva, tendo a autoridade ministerial tomado conhecimento;

Considerando que a SECEX./MS propõe sejam as presentes contas julgadas regulares com ressalva, dando-se quitação aos responsáveis, sem prejuízo de se determinar ao mencionado Conselho que se abstenha de admitir pessoal sem a realização de concurso público, ante o disposto no art. 37, II, da Constituiçāo Federal;

Considerando que o Ministério Público, embora se manifeste pele regularidade com ressalva das presentes contas, entende ilegal a admissão de três servidores por não terem sido precedidas de concurso público;

Considerando que este Tribunal, em casos análogos, tem determinado às entidades congêneres que se abstenham de admitir pessoal sem a realizaçāo de prévio concurso público, ante o disposto no art. 37, II, da Constituiçāo Federal, e na Súmula 231 da Jurisprudência desta Corte de Contas (v.g., Acórdão n. 
209/98 - TCU/2a Câmara - in Ata n. 18/98; Acórdāo n. 212/98 - TCU/2a Câmara - in Ata n. 19/98; Acórdāo n. 213/98 - TCU/2a Câmara - in Ata n. 19/98; Acórdão n. 248/98 - TCU/2a Câmara - in Ata n. 24/98; Acórdão n. 313/98 - TCU/2a Câmara - in Ata n. 30/98; Acórdão n. 329/98 - TCU/2a. Câmara - in Ata n. 31/98; Acórdão n. 390/98 - TCU/2a Câmara - in Ata n. 35/98):

ACORDAM os Ministros do Tribunal de Contas da União, reunidos em Sessão da 2a Câmara, em, com fundamento nos arts. $1^{2}$, inciso I, 16, inciso II, 18 e 23, inciso II, da Lei n. 8.443/92, julgar as presentes contas regulares com ressalva, dando quitação aos responsáveis em epígrafe, sem prejuízo de determinar ao Conselho Regional de Contabilidade de Mato Grosso do Sul - CRC/MS que se abstenha de admitir pessoal sem a rea- lização de prévio concurso público, ante o disposto no art. 37, II, da Constituição Federal, e na Súmula 231 da Jurisprudência deste Tribunal.

9. Ata no 37/98 - 2a Câmara.

10. Data da Sessão: 26/10/1998 — Extraordinária.

11. Especificação do quorum:

11.1. Ministros presentes: Adhemar Paladini Ghisi (Presidente), Valmir Campelo e os Ministros-Substitutos José Antonio Barreto de Macedo (Relator) e Benjamin Zymler.

ADHEMAR PALADINI GHISI, Presidente

JOSÉ ANTONIO BARRETO DE MACEDO, Ministro-Relator

Fui presente: MARINUS EDUARDO DE VRIES MARSICO, Repres. do Ministério Público 